\title{
DNA-Templated Fluorescent Silver Nanoclusters Inhibit Bacterial Growth While Being Non-Toxic to Mammalian Cells
}

\author{
Lewis Rolband ${ }^{1, \dagger}$, Liam Yourston ${ }^{2, \dagger}$, Morgan Chandler ${ }^{1,+}$, Damian Beasock ${ }^{1, \dagger}{ }^{\dagger}$,eyla Danai ${ }^{1}$, Seraphim Kozlov ${ }^{1}$, \\ Nolan Marshall ${ }^{2}$, Oleg Shevchenko ${ }^{1}$, Alexey V. Krasnoslobodtsev ${ }^{2, * \mathbb{D}}$ and Kirill A. Afonin ${ }^{1, * \mathbb{D}}$ \\ 1 Nanoscale Science Program, Department of Chemistry, University of North Carolina at Charlotte, \\ Charlotte, NC 28223, USA; lrolband@uncc.edu (L.R.); mchand11@uncc.edu (M.C.); \\ dbeasock@uncc.edu (D.B.); ldanaino@uncc.edu (L.D.); sskozlov04@gmail.com (S.K.); \\ oshevche@uncc.edu (O.S.) \\ 2 Department of Physics, University of Nebraska at Omaha, Omaha, NE 68182, USA; \\ lyourston@unomaha.edu (L.Y.); nmarshall@unomaha.edu (N.M.) \\ * Correspondence: akrasnos@unomaha.edu (A.V.K.); kafonin@uncc.edu (K.A.A.) \\ + These authors contributed equally to this work.
}

Citation: Rolband, L.; Yourston, L.; Chandler, M.; Beasock, D.; Danai, L.; Kozlov, S.; Marshall, N.; Shevchenko, O.; Krasnoslobodtsev, A.V.; Afonin, K.A. DNA-Templated Fluorescent Silver Nanoclusters Inhibit Bacterial Growth While Being Non-Toxic to Mammalian Cells. Molecules 2021, 26, 4045. https://doi.org/10.3390/ molecules26134045

Academic Editors: Jussara Amato and Ashok Kakkar

Received: 12 April 2021

Accepted: 29 June 2021

Published: 1 July 2021

Publisher's Note: MDPI stays neutral with regard to jurisdictional claims in published maps and institutional affiliations.

Copyright: (c) 2021 by the authors. Licensee MDPI, Basel, Switzerland. This article is an open access article distributed under the terms and conditions of the Creative Commons Attribution (CC BY) license (https:/ / creativecommons.org/licenses/by/ $4.0 /)$.

\begin{abstract}
Silver has a long history of antibacterial effectiveness. The combination of atomically precise metal nanoclusters with the field of nucleic acid nanotechnology has given rise to DNAtemplated silver nanoclusters (DNA-AgNCs) which can be engineered with reproducible and unique fluorescent properties and antibacterial activity. Furthermore, cytosine-rich single-stranded DNA oligonucleotides designed to fold into hairpin structures improve the stability of AgNCs and additionally modulate their antibacterial properties and the quality of observed fluorescent signals. In this work, we characterize the sequence-specific fluorescence and composition of four representative DNA-AgNCs, compare their corresponding antibacterial effectiveness at different $\mathrm{pH}$, and assess cytotoxicity to several mammalian cell lines.
\end{abstract}

Keywords: DNA; silver; AgNC; nanocluster; antibacterial; fluorescence

\section{Introduction}

The formation of silver nanoclusters (AgNCs) on single-stranded (ss) DNA templates has been shown to promote the unique optical properties defined by the sequences of the DNA strands [1-3]. Out of all available coordination sites on nucleobases, silver cations demonstrate the highest affinity for the N3 of cytosines, and therefore cytosinerich ssDNAs become efficient capping-agents for AgNC formation [4-6]. The size and shape of AgNCs are regulated by rationally designed and chemically synthesized short DNA oligonucleotides with different numbers of single-stranded cytosines embedded in secondary and tertiary DNA structures such as hairpin loops, i-motifs, and G-quadruplexes, to name a few [4-6]. The optical properties of DNA-AgNCs are dictated by their size, as the appearance of the characteristic fluorescence is possible for nanoclusters comprised of only a few silver atoms. At this nanometer size, a continuous density of electronic energy states present in bulk silver breaks up and a band gap in the material becomes apparent [1-8]. This, in turn, causes a molecule-like behavior of AgNCs with discrete energy states allowing for size-dependent fluorescence to occur [7-9]. DNA-capped AgNCs are also generally more resistant to photobleaching when compared to traditional organic fluorophores or fluorescent proteins, and this property begets the application of DNA-AgNCs in a variety of nanophotonics and biosensing/biomedical applications [10-13]. While nanophotonics and biosensing with DNA-AgNCs' advantageous optical properties have been widely probed and studied, other practical uses of AgNCs remain unexplored. Since the main functional component of DNA-AgNCs is silver, applications based on effects known for this element may prove useful. Various forms of silver, including ions and silver nanoparticles, 
are well-documented to have antibacterial efficacy [14-17]. Several groups have shown DNA-AgNCs to be effective against both Gram-negative and Gram-positive bacteria in liquid cultures [18-20] and against the formation of biofilms when aptamers for increased targeting and binding of the bacteria of interest were introduced [21,22]. However, the underlying mechanisms and relationship between the fluorescent properties of DNAAgNCs and their antibacterial actions are still understudied and poorly understood. AgNCs offer a large surface-to-volume ratio and are composed of both forms of silver: cationic $\left(\mathrm{Ag}^{+}\right)$and neutral $\left(\mathrm{Ag}^{0}\right)$, thereby providing further advantages over solid silver, silver salts, or silver nanoparticles.

We reason that understanding and linking optical and antibacterial properties of DNA-AgNCs may pave the way to the development of next generation antibacterial agents with high potency and regulated activity. Our current work includes four representative DNA hairpins that template the formation of DNA-AgNCs with four distinct colors and investigates their optical properties in relation to antibacterial activity measured at different $\mathrm{pH}$, as well as in relation to cytotoxicity assessed for several human cell lines. The use of antibacterial DNA-AgNCs formed on DNA hairpins becomes advantageous for various antibacterial formulations and opens broader possibilities for DNA nanotechnology due to the relative structural stability of the hairpins and their inability to participate in any undesirable base-pairings, thus not interfering with any other DNA nanodesigns. As proof-of-concept work, we explore the use of DNA-AgNC forming hairpins with odd numbers of consecutive cytosines (C7, C9, C11, or C13) in their loop compositions.

\section{Results}

\subsection{Template Design}

Cytosine-rich ssDNAs are suitable capping agents for templating stable DNA-AgNCs due to cytosine's high affinity for silver ions, $\mathrm{Ag}^{+}$. Various sequences have been reported to stabilize clusters with unique optical properties, including bright emission bands in the visible part of the spectrum and excitation bands in the UV and visible regions. The emission wavelengths can be modulated by choosing a specific DNA sequence and various colors (e.g., yellow, green, orange, red as shown in Figure 1) of DNA-AgNCs have been reported based on prevalent emission wavelengths for a particular nanocluster.

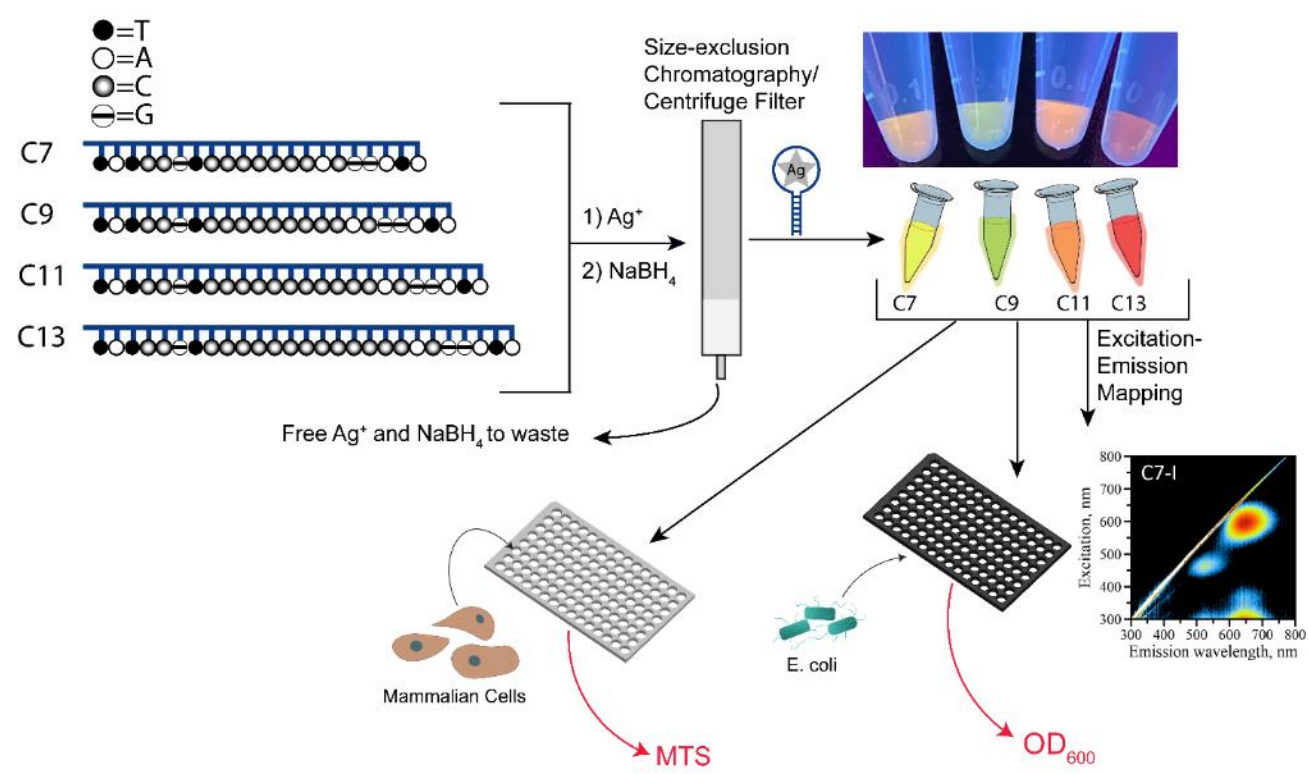

Figure 1. Experimental flow of DNA-AgNC synthesis, purification, and analysis. The embedded image shows DNA-AgNCs after their purification upon UV excitation on a transilluminator.

While the parameters that define emissive properties of DNA-AgNCs are still not well understood, it is generally accepted that shape, size, and overall charge state of the AgNC 
are among the main contributors. We hypothesize that the same factors are responsible for modulating the antibacterial activity of the DNA-AgNCs. While cytosine-rich ssDNAs have been widely used in synthesizing AgNCs, these sequences are prone to forming alternative DNA structures [23]. Such alternative structures include i-motif and non-canonical C-Ag-C base paring facilitated by the presence of silver cations. We have compared properties of two C12-containing templates in which one is an opened ssDNA and another is a sequence embedded in a hairpin loop. The results (Supporting Figure S1) clearly show the differences observed for these two sequences after DNA-AgNC formation. As evident from AFM images (Supporting Figure S1A,B), the single-stranded template shows various degrees of polymerization, while the hairpin-loop template does not polymerize, forming individual DNA-AgNCs. These results agree well with our recent study demonstrating that the formation of alternative DNA structures in the presence of $\mathrm{Ag}^{+}$drives the polymerization of various sequences containing single-stranded (ss) C-rich stretches [23]. Additionally, such polymerization also alters fluorescence properties of AgNCs (Supporting Figure S1C,D). Hairpin-looped structures feature one single fluorescence peak for $C_{12}$ sequence while single-stranded templates show multiple peaks, suggesting the formation of AgNCs with various sizes and shapes due to variety of the polymerized templates [23]. To avoid structural and functional uncertainties associated with $\mathrm{ss}_{\mathrm{N}}$ template sequences and to make the structures suitable for further implementation in nanodesign, we have chosen to work only with DNA hairpin templates wherein the $C_{N}$ sequence forms the loop of the hairpin structure. Four representative templates were constructed with the same doublestranded stem and a loop with a variable number of ssCs (C7, C9, C11, and C13). This design gradually increases the number of binding sites for silver and makes the size of the loop larger (Figure 1) [3,24]. An odd number of cytosines in the loop with $+2 \mathrm{C}$ steps was intended to noticeably alter properties of the DNA-AgNCs with fluorescent colors covering the entire visible spectral region (Figure 1). We reasoned that such substantial optical differences would provide an insight into which factors modulate the antibacterial activity of the DNA-AgNCs and how antibacterial activity correlates with the optical signatures of individual DNA-AgNCs. Incubation of the looped DNA templates with silver nitrate and subsequent reduction of silver using sodium borohydride results in the formation of optically active nanoclusters with bright emissions (Figures 1 and 2). Supporting Figure S8 shows UV-Vis spectra of all four purified AgNC samples immediately after their formation.

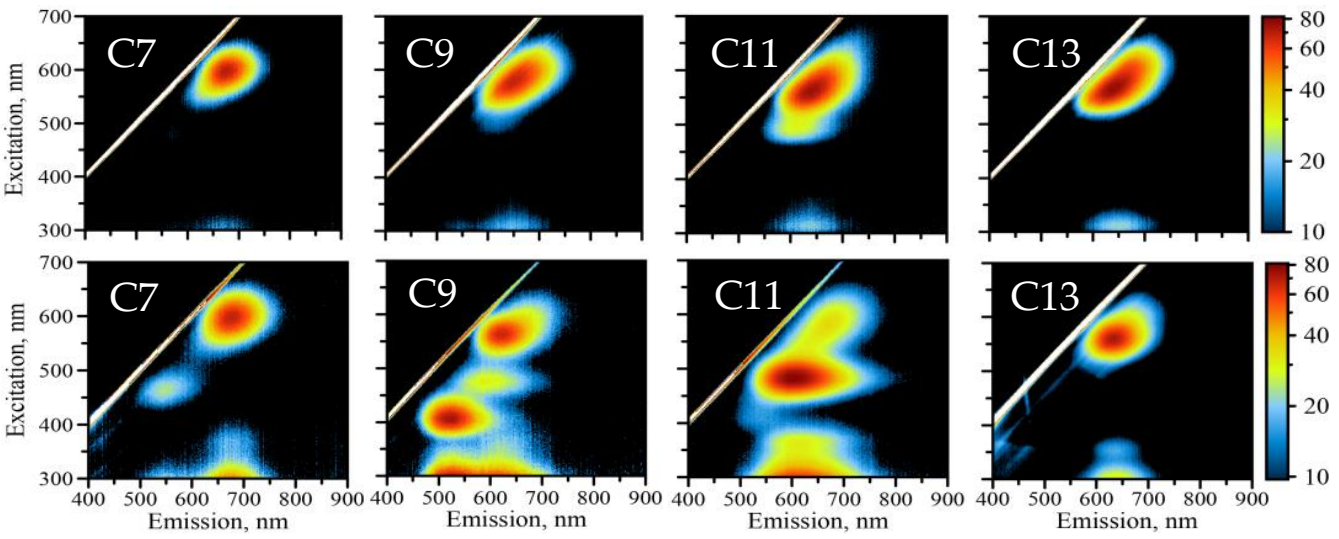

Figure 2. Fluorescence measurements of DNA-AgNCs. Excitation-emission matrix spectroscopy: top panel shows the initial readings of freshly made DNA-AgNCs, bottom panel corresponds to the analysis of samples aged over a period of two weeks (dual fluorescence pattern with both green and red peaks is typical for freshly prepared AgNCs producing distinct colors shown in Figure 1).

\subsection{Fluorescence}

The formation of DNA-AgNCs is tracked by the changes in solution that are observed after the addition of silver nitrate and sodium borohydride reducing agent followed by incubation in the dark for $24 \mathrm{~h}$. We have characterized the optical properties of these 
DNA-AgNCs using fluorescence excitation-emission matrix spectroscopy (EEM). EEM represents the excitation-emission relationships of the optical response of the DNA-AgNCs presented as 2D contour maps [25]. Figure 2 shows EEM maps for all four DNA-AgNCs in the 300-800 $\mathrm{nm}$ range for the excitation while recording the emission spectrum spanning 300-800 nm wavelengths. Initial readings of the EEMs after purification (top panel of Figure 2) indicates that all four samples show a great degree of similarity in the behavior of emission. All four samples are dominated by one peak in the red region of the spectrum. While similar in general, the peaks show detectable differences.

In Table 1, we summarize peak positions for the maximum excitation and maximum emission for all four DNA-AgNCs. It appears that smaller loop DNA-AgNCs have maxima for both excitation and emission shifted to longer wavelengths. It is very pronounced for C7 and C9 with $\lambda_{\mathrm{EXC}} / \lambda_{\mathrm{EM}}=600 / 685 \mathrm{~nm}$ and $\lambda_{\mathrm{EXC}} / \lambda_{\mathrm{EM}}=580 / 661 \mathrm{~nm}$, respectively. Further shifts to $\lambda_{\mathrm{EXC}} / \lambda_{\mathrm{EM}}=562 / 647 \mathrm{~nm}$ and $\lambda_{\mathrm{EXC}} / \lambda_{\mathrm{EM}}=562 / 645 \mathrm{~nm}$ are observed for C11 and C13, respectively. C11 DNA-AgNC also features an extra shoulder of emission at shorter excitation wavelengths. $\mathrm{C} 9, \mathrm{C} 11$, and $\mathrm{C} 13$ peaks appear to be elongated featuring red edge emission shift (REES) as reported previously and is common for AgNCs [23,26,27]. Interestingly, C7 DNA-AgNC does not have REES-based elongation of the emission peak that is well-pronounced for other samples. These observations emphasize the differences of DNA-AgNCs formed by the four looped templates despite all samples having "red" emission.

Table 1. Spectral position of excitation and emission for "red" emitting peak in initial EEMs.

\begin{tabular}{lllll}
\hline Wavelength, nm & C7 & C9 & C11 & C13 \\
\hline EXC $_{\text {MAX }}$ & 600 & 580 & 562 & 562 \\
FLU $_{\text {MAX }}$ & 685 & 661 & 647 & 645 \\
\hline
\end{tabular}

The differences in observed optical properties intensify further as samples are allowed to age. Changes in emission pattern with time develop very quickly during "maturation" stage of the AgNCs typical for our preparation procedure. These changes represent the conversion of AgNCs from "red" to "green" emission upon interaction with ambient conditions as we have previously reported [26]. "Red" to "green" conversion can be linked to the interactions of AgNCs with species dissolved in the solution that are capable of oxidizing silver atoms $\left(\mathrm{Ag}^{0} \rightarrow \mathrm{Ag}^{+}\right)$, such as molecular oxygen [26]. Many reports documented the "blue" shift with aging and some protocols call for bubbling oxygen through to stimulate this transition [28]. All four of our samples also experience such "blue" shift and eventually develop a pattern of multi-peaked emission spectra with some samples more noticeable than others (for example, C9 vs. C13). Figure 2 summarizes in detail all changes in emission patterns when C7-C13 DNA-AgNCs age over a period of two weeks. The appearance of additional emission peaks in the "green" region are obvious for C7, C9, and C11, while C13 remained primarily as a single peak. The changes in C13 DNA-AgNCs include the loss of elongated shape with the near-IR part of the peak disappearing over time. Shorter loops C7, C9, and C11 develop an obvious multipeak excitation-emission pattern over time. These new peaks appear in the "orange" and "green" spectral regions. Additionally, these peaks differ significantly in their position and intensity. C7 DNA-AgNCs have only one new peak of $\lambda_{\mathrm{EXC}} / \lambda_{\mathrm{EM}}=465 / 547 \mathrm{~nm}$ - "green." The intensity of this new peak is $27 \%$ the intensity of the original "red" peak. Both C9 and C11 have multi-peak patterns of newly appeared "orange" and "green" emission labeled $\mathrm{O}$ (longer wavelengths) and $\mathrm{G}$ (shorter wavelengths). The positions of these two new peaks are very similar for both $C 9$ and C11 DNA-AgNCs: $\lambda_{\mathrm{EXC}} / \lambda_{\mathrm{EM}}=475 / 606 \mathrm{~nm}$ $(\mathrm{O}-\mathrm{C} 9), \lambda_{\mathrm{EXC}} / \lambda_{\mathrm{EM}}=480 / 606 \mathrm{~nm}(\mathrm{O}-\mathrm{C} 11), \lambda_{\mathrm{EXC}} / \lambda_{\mathrm{EM}}=408 / 530 \mathrm{~nm}(\mathrm{G}-\mathrm{C} 9)$, and $\lambda_{\mathrm{EXC}} / \lambda_{\mathrm{EM}}$ $=410 / 536 \mathrm{~nm}$ (G-C11). Similar spectral positions indicate the same nature of "green" states for both C9 and C11 DNA-AgNCs. The differences for these two samples, however, include the position of the "red" peak as listed in Table 1. Another major difference is the relative intensities of orange and green peaks, $\mathrm{O}$ and G. O peak dominates in the C11 sample, 
while $\mathrm{G}$ is more pronounced in the $\mathrm{C} 9$ sample. The following are the relative intensities as compared to the original "red" peak: 22\% (O-C9), 360\% (O-C11), 112\% (G-C9), and 29\% (G-C11). The observed intensities suggest that C9 DNA-AgNCs primarily stabilize G state while C11 DNA-AgNCs prefer O. The O peak is not observed in the fluorescence of the aged C7 sample, while C13 remains "red" during aging.

To complete the description of the emissive properties of C7-C13 DNA-AgNCs, we also visualized the emission of nanoclusters under UV excitation on a trans-illuminator (at $254 \mathrm{~nm}$ ). Such excitation is typically discussed as a means of excitation via DNA bases that contact silver atoms in the nanocluster. The $254 \mathrm{~nm}$ excitation results in a color palette of the employed samples (colors under trans-illuminator excitation, Figure 1-top). This picture reflects the rich emission pattern observed for C7-C13 DNA-AgNCs in the visible part of the spectrum.

\subsection{Cell Culture Experiments}

To assess the relative effects of representative DNA-AgNCs on bacterial cells, TOP10F' E. coli are grown in liquid cultures and treated with the panel of DNA-AgNCs at a final concentration of $4 \mu \mathrm{M}$ DNA (Figure 3A). A decrease in the bacterial growth is observed over a $20 \mathrm{~h}$ period for all $E$. coli cultures treated with DNA-AgNCs when compared to the non-treated control. There is a strong dose-dependence noted for all DNA-AgNCs (Supporting Figure S2) with $4 \mu \mathrm{M}$ to be the lowest DNA concentration that shows reasonable antibacterial effectiveness for all constructs. As such, all experiments are carried out at 4 $\mu \mathrm{M}$ in order to best resolve differences between four tested DNA-AgNCs. To quantitatively examine the inhibition of $E$. coli growth, we compare the changes in the amount of time $\left(\Delta \mathrm{t}_{1 / 2}\right)$ required for bacteria cultured with each DNA-AgNC to grow to half of their maximum optical density when referenced to untreated cells from the same experimental group. $\mathrm{C} 13$ is the most effective DNA-AgNC at slowing bacterial growth as the calculated $\Delta \mathrm{t}_{1 / 2}$ for $\mathrm{C} 7, \mathrm{C} 9, \mathrm{C} 11$, and C13, shown with their $95 \%$ confidence intervals, are $5.5 \pm 0.2 \mathrm{~h}, 5.8 \pm 0.3 \mathrm{~h}$, $8.8 \pm 0.2 \mathrm{~h}$, and $10.7 \pm 0.2 \mathrm{~h}$, respectively. The effect of free silver at the concentrations used to synthesize the DNA-AgNCs can be considered minimal since the control experiment with $650 \mu \mathrm{M}$ of $\mathrm{Ag}^{+}$, the highest of the concentrations used for $C_{N}$ synthesis, has a minimal effect on the growth curve after being reduced with $\mathrm{NaBH}_{4}$ (Supporting Figure S3). The antibacterial effect of the DNA-AgNCs greatly increases at lower $\mathrm{pH}$. When E. coli grown in $\mathrm{pH}$ 5.5-buffered LB are treated with $4 \mu \mathrm{M}$ of each DNA-AgNC, the growth is nearly fully inhibited over the entire $20 \mathrm{~h}$ (Figure 3A). From these experiments, the performance of $\mathrm{C} 7$ and $\mathrm{C} 9$ as antibacterial agents are similar, though it is clear that $\mathrm{C} 13$ outperforms C11 significantly. From these data, it appears that there may be a correlation between the number of cytosines and the antibacterial efficacy of the DNA-AgNC for larger hairpins. 

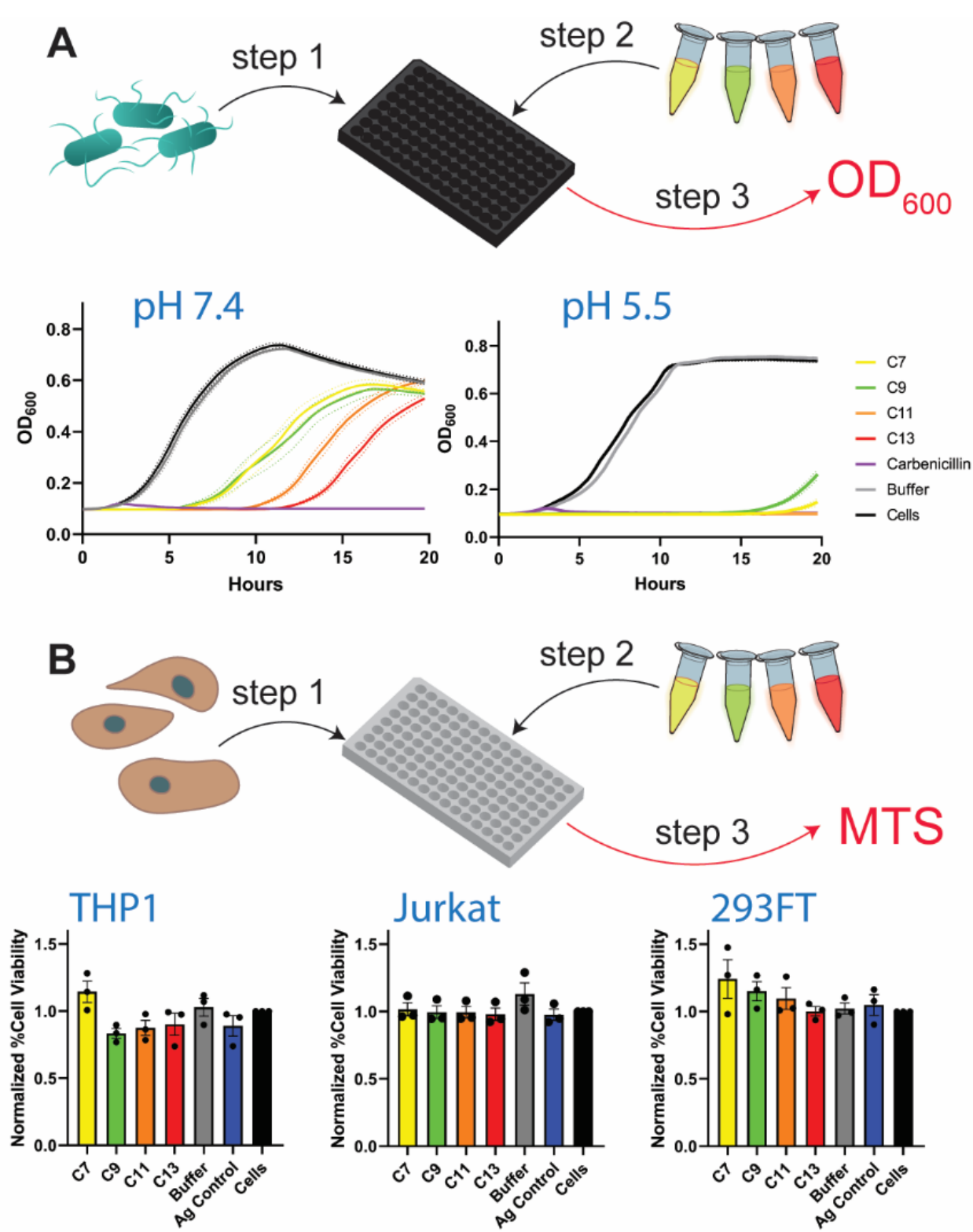

Figure 3. Biological activity of DNA-AgNCs. (A) The growth curves of E. coli when treated with 4 $\mu \mathrm{M}$ DNA-AgNC are shown at $\mathrm{pH} 7.4$ (the $\mathrm{pH}$ of standard LB) and $\mathrm{pH}$ 5.5. The standard error of the mean of each measurement is shown as a dotted line on both sides of the solid line in the same color. The lines for $\mathrm{C} 11, \mathrm{C} 13$, and Carbenicillin overlap at $\mathrm{pH}$ 5.5. (B) The normalized cell viability of THP1-Dual ${ }^{\mathrm{TM}}$, Jurkat, and 293FT cells after incubation with $4 \mu \mathrm{M}$ AgNC for $20 \mathrm{~h}$, as assessed by MTS assay.

To test the same conditions in mammalian cells, we use several human cell lines and all DNA-AgNCs are again introduced at a $4 \mu \mathrm{M}$ final concentration. The cell viability is assessed after $20 \mathrm{~h}$ of incubation using an MTS assay (Figure 3B). No statistically significant reduction in cell viability is observed after incubation with DNA-AgNCs for Jurkat, THP1, or $293 \mathrm{FT}$ cells. To ensure the safety of DNA-AgNCs for mammalian cells, the same experiments are repeated at a final concentration of $8 \mu \mathrm{M}$ DNA-AgNC with all three cell lines and the results are similar (Supporting Figure S4). Therefore, AgNCs remain non-toxic to mammalian cells at concentrations two-fold higher than required to efficiently inhibit bacterial growth. 


\subsection{Stoichiometry Determination}

In order to quantify the number of silver atoms bound to each ssDNA oligonucleotide, energy dispersive X-ray spectroscopy (EDS) elemental analysis is performed and micrographs of dried AgNC solutions are recorded using scanning electron microscopy. The ratio of the relative atomic percentages of the $\mathrm{Ag}$ and $\mathrm{P}$ calculated from the EDS spectrum are used for evaluating the stoichiometric ratio of silver per hairpin-loop DNA template. From these experiments, we determine that each C7 DNA-AgNC binds an average of 9.9 \pm 0.6 silver atoms ( \pm SEM), C9 DNA-AgNC binds an average of $8.5 \pm 0.5$ silver atoms, C11 DNA-AgNC binds an average of $11.7 \pm 0.5$ silver atoms, and C13 DNA-AgNC binds an average of $10.2 \pm 0.9$ silver atoms. The differences in the number of silver atoms bound were not found to be statistically significant between each templating strand. A representative micrograph of a DNA-AgNC sample is shown in Figure 4, and the micrographs of all samples analyzed by EDS are shown in the Supplementary Materials (Supporting Figure S5).

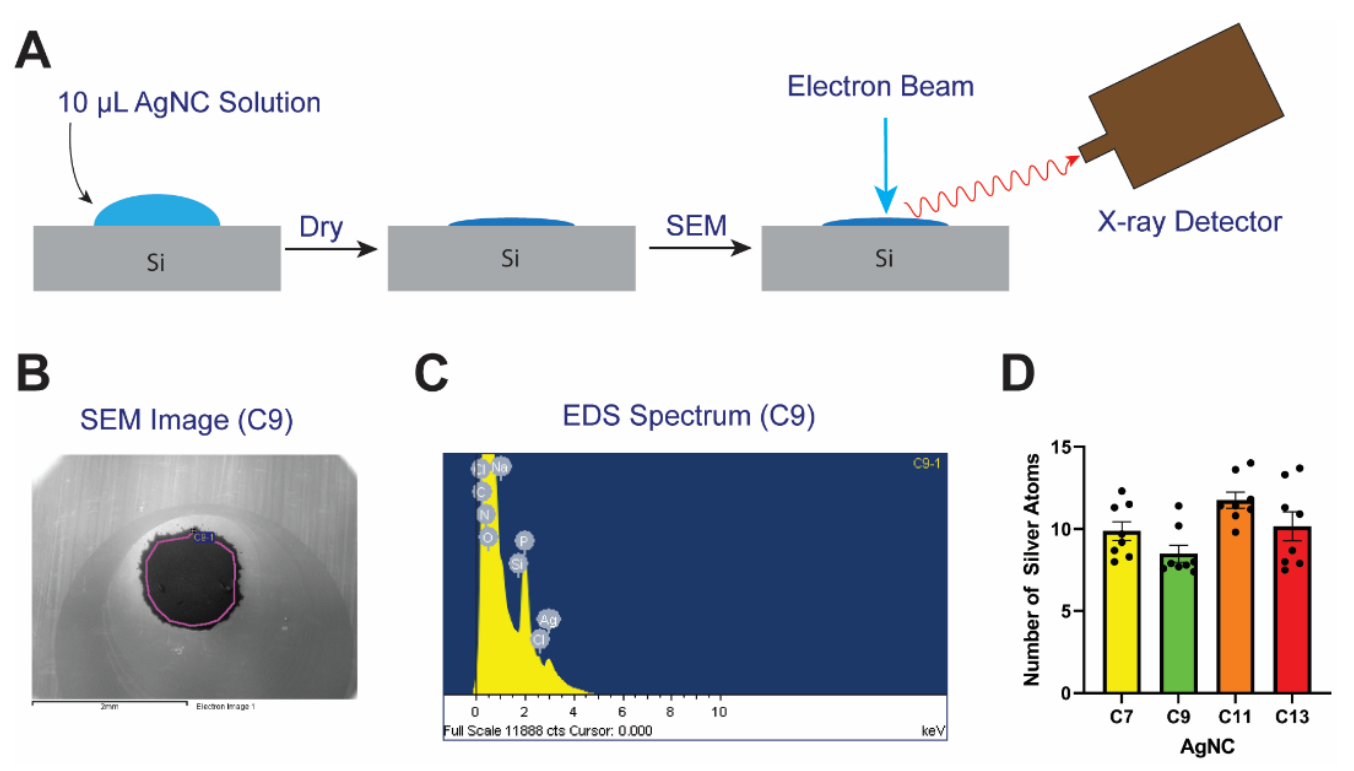

Figure 4. (A) The general workflow for the SEM and EDS experiments is shown. The drying is done at ambient conditions with the silicon wafer covered by a Petri dish. (B) A representative SEM image is shown of a DNA-AgNC C9 sample and (C) the raw EDS spectrum of the same sample. The purple line in (B) defines the outer perimeter of the area that is scanned to obtain the EDS spectrum. (D) The number of bound silver atoms on each templating DNA hairpin is shown as determined by EDS. Error bars shown as a dotted line on both sides of the solid line are the standard error of the mean for each measurement.

\section{Discussion}

Silver has long been used as a disinfectant. The most recent applications include the use of silver nanoparticles in many different areas including food packaging, water and air disinfection, the textile sector, and medical applications (Silver Soaker ${ }^{\circledR}$ Catheters, Acticoat $^{\mathrm{TM}}$, SilvaSorb ${ }^{\circledR}$ Gel) $[29,30]$. The search for new therapeutic agents to combat multidrug resistant bacteria is ongoing. While silver nanoparticles have been recently extensively studied for their use as antibacterial agents [31], novel silver nanoclusters have been largely overlooked [18] primarily because most studies have focused on biosensing applications due to the unique optical properties of AgNCs [27,32,33]. DNA-AgNCs have several advantages which position them as excellent candidates for antibacterial applications. First, DNA-AgNCs are small in size - they are comprised of only a few atoms of silver capped with stabilizing cytosine-rich ssDNA oligonucleotides. Since DNA-AgNCs are bound to DNA, in addition to serving as a host for AgNCs, DNA can also be utilized for embedding AgNCs into a structured network of functional assemblies leading to novel properties and 
functions of hybrid nanomaterials [23,26]. In this study, we show that AgNCs are capable of inhibiting bacterial growth at a much lower concentration $(4 \mu \mathrm{M})$ than carbenicillin $(132 \mu \mathrm{M})$, which is a bactericidal antibiotic from the penicillin group and was used as a positive control in this study. We confirm, herein, that DNA-AgNCs show very little toxicity against human cells. In addition to serving as a template for AgNC synthesis, DNA templates may further contribute to better solubility and biocompatibility of clusters. Thus, DNA-AgNCs could potentially be used against a broad range of various bacteria without harmful side effects. Furthermore, the robust fluorescence of AgNCs can be coupled with biocompatibility and antibacterial properties to produce label-free bioimaging agents with dual purpose.

Our additional experiments indicate that DNA-AgNCs exhibit antibacterial activity against Lactobacilli (Supporting Figure S6), suggesting that DNA-AgNCs might cause undesirable effects to the gut microbiota, and should be avoided in applications involving oral ingestion of these materials, e.g., in food packaging. This is especially concerning, given the increased antibacterial efficacy of AgNCs at lower $\mathrm{pH}$ (Figure 3A). Previous work has shown that decreasing the $\mathrm{pH}$ will increase the antibacterial efficacy of silver nanoparticles that likely arises from an increased production of reactive oxygen species and that DNAAgNCs are capable of catalyzing the production of reactive oxygen species [18,34]. It is possible, therefore, that DNA-AgNCs produce an increased amount of reactive oxygen species as $\mathrm{pH}$ decreases. Another possibility for the increased antibacterial activity of DNA$\mathrm{AgNCs}$ at lower $\mathrm{pH}$ is leaching silver into solution through cytosine protonation. However, the $\mathrm{pK}_{\mathrm{a}}$ of cytosine is close to 4.4 , so less than $10 \%$ of cytosines would be expected to be protonated at $\mathrm{pH}=5.5$ [35]. Additionally, DNA-AgNCs retain their fluorescence pattern over a wide $\mathrm{pH}$ range, down to a $\mathrm{pH}$ of 5, implying stabile character of the DNA-AgNCs at $\mathrm{pH}=5.5$ [36]. Therefore, we consider it unlikely that the decreased $\mathrm{pH}$ would cause silver ions to leach from the AgNC causing enhanced inhibition of bacterial growth.

We show that C13 DNA-AgNC produces the highest antibacterial activity among the four studied DNA template sequences followed by C11, while C7 and C9 DNA-AgNCs show lower activity (Figure 3A). While several factors might contribute to antibacterial activity, the number of silver atoms comprising the AgNCs does not appear to be the decisive factor. Using EDS elemental analysis, we confirmed that there is no statistical significance in the number of silver atoms bound by each DNA-AgNC (Figure 4A). It is unlikely that the amount of silver in the DNA-AgNCs determines their antibacterial properties as all templates stabilize clusters of nearly the same size with $N \approx 10-11$ bound in them. Our observation is supported by a previous report which also ruled out the amount of silver atoms per cluster [18]. Emission color has been proposed to correlate with DNA-AgNCs' antibacterial properties with "red" emissive clusters being the most active [18]. We also turned to fluorescence properties in search of a possible explanation for the antibacterial activity of DNA-AgNCs. It is unclear how exactly DNA-AgNCs act in terms of antibacterial properties and this uncertainty in their mechanism of antibacterial action has triggered the current study. There are clear changes in fluorescent properties of DNA-AgNCs which we can correlate with the increased antibacterial activity of AgNCs. It appears that a single-peak emission pattern might be the key. The mere presence of "red" fluorescence does not define antibacterial properties; all samples are "red" initially, but the abilities to inhibit bacterial growth differ among C13, C11 and C9, C7. C13 remains "red" during aging while $\mathrm{C} 11$ effectively converts to "orange." At the same time, $\mathrm{C} 13$ provides better antibacterial efficacy as compared to C11. Additionally, C7 remains primarily "red" while its activity is lower than C11 and C13. C9 is the only sample that develops a "green" peak with high intensity, but it is also less effective at inhibiting bacterial growth. As such, we hypothesize that the stability of the "red" fluorescence upon aging may be one of the most decisive factors for the antibacterial efficacy of DNA-AgNCs.

It is commonly accepted that DNA-AgNCs include both $\mathrm{Ag}^{0}$ and $\mathrm{Ag}^{+}$atoms in their composition. The ratio of $\mathrm{Ag}^{0} / \mathrm{Ag}^{+}$defines the overall charge state and the color of the nanocluster's emission [37]. It has been proposed that distinct "green" and "red" fluorescence 
occurs for a "magic number" of neutral silver atoms in the nanocluster $[37,38]$. Four neutral atoms produce green fluorescence and six $\mathrm{Ag}^{0}$ atoms produce red fluorescence regardless of the number of $\mathrm{Ag}^{+}$[37]. Recent studies indicated that such conversion does not change the overall number of silver, $N$, in the cluster as this conversion is reversible [26,31].

"Red," "orange," and "green" emissive states of AgNCs that we observe may represent different ratios of $\mathrm{Ag}^{+}$to $\mathrm{Ag}^{0}$. Aging of the samples can therefore be explained by the interaction of AgNCs with species dissolved in the solution that are capable of oxidizing silver atoms $\left(\mathrm{Ag}^{0} \rightarrow \mathrm{Ag}^{+}\right)$. For example, dissolved "molecular oxygen" might effectively convert "red" to "orange" and to "green" emitting species. Controlled oxidation with hydrogen peroxide confirms our conclusion (Supporting Figure S8). The addition of hydrogen peroxide gradually converts emissive patterns which resembles "aging" of all samples. We have previously confirmed that gradual aging or oxidation due to addition of hydrogen peroxide can be reversed by re-reduction of resultant AgNCs [26]. This process is reversible and can be done multiple times suggesting that red-ox state of the AgNCs rather than size plays a critical role in fluorescence pattern that we observe here for hairpin-loop templated DNA-AgNCs. Many studies relate the antibacterial activity of silver nanoparticles to the oxidative release of $\mathrm{Ag}^{+}$[39]. In this regard, DNA-AgNCs already have silver ions in their composition and can therefore act as antibacterial agents. Furthermore, the ratio of $\mathrm{Ag}^{+} / \mathrm{Ag}^{0}$ can modulate the antibacterial activity of DNA-AgNCs. It is tempting to suggest that the increased number of silver ions in DNA-AgNCs may explain higher antibacterial activity. However, C9 is dominated by "green" emitting species which would supposedly have the highest number of cations in the DNA-AgNC composition, while we observe that C9 has the second lowest antibacterial effect. It is possible that the looped hairpin templates used herein while varying in length may have different protective properties for DNA-AgNCs depending on the final conformation of the loop wrapping around silver nanoclusters. For example, faster conversion of C13 to a nonemitting species might indicate lesser protection of the clusters and thus correlate better with higher antibacterial activity of C13. Additional studies will be required to identify whether intact DNA-AgNCs act as the antibacterial agent or if their activity requires nanocluster dissolution with the release of silver ions into the solution.

Another possible explanation for different activities observed for the four analyzed samples is that the nature of emissive and non-emissive states may play a role. We observed that all four samples age and react with hydrogen peroxide very differently (Supporting Figure S7). It is also apparent that partial oxidation is involved in "red" to "orange" or "red" to "green" conversion of emissive DNA-AgNC states. We have evaluated the rate of "red" peak conversion as a function of hydrogen peroxide concentration (Figure 5) for all four DNA-AgNCs using a modified Stern-Volmer relationship (Equation (1)) [40].

$$
F_{0} / F=\left(1+K_{D} C_{H 2 O 2}\right)\left(1+K_{S} C_{H 2 O 2}\right)
$$
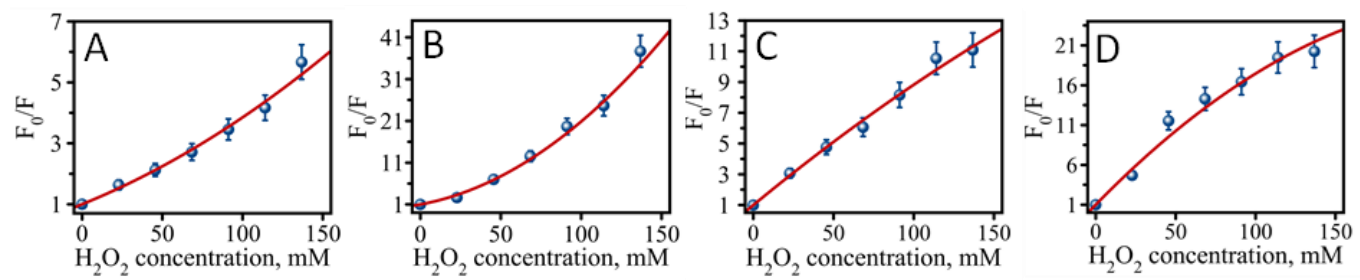

Figure 5. Stern-Volmer plots for (A) C7 DNA-AgNCs, (B) C9 DNA-AgNCs, (C) C11 DNA-AgNCs, (D) C13 DNA-AgNCs. Data points were fitted with Equation (1), which considers two possible quenching mechanisms: static and dynamic.

Generally, a linear Stern-Volmer plot indicates a single class of fluorophores which are all equally vulnerable to quenching by hydrogen peroxide [40]. All four DNA-AgNC samples show non-linear $\mathrm{F}_{0} / \mathrm{F}$ vs. $\mathrm{H}_{2} \mathrm{O}_{2}$ concentration dependence (Figure 5). This sug- 
gests a complex nature of fluorescence quenching with at least two deactivation pathways: intermolecular quenching due to $\mathrm{H}_{2} \mathrm{O}_{2}$ (dynamic quenching, $\mathrm{K}_{\mathrm{D}}$, most likely due to intersystem crossing from singlet $\mathrm{S}^{*}$ to triplet $\mathrm{T}^{*}$ ) and intramolecular conversion of "red" to "orange" or "green" (static quenching, $\mathrm{K}_{\mathrm{S}}$, due to change of the overall charge state of AgNC). While C7 and C9 DNA-AgNCs exhibit slightly upward curvature, C11 and C13 show clear downward curvature. This observation indicates that these two groups have different mechanisms of quenching while interacting with hydrogen peroxide. Typically, downward curvature is associated with fluorophores which are inaccessible to the quencher, suggesting a more protective nature of larger loops [40]. Interestingly, C13 also shows the highest antibacterial activity and the largest downward curvature among the studied C-loop templates. While it is difficult to specify exact details of interactions between the "quencher" and certain states of AgNCs without further studies, it is apparent that the charge state of the DNA-AgNC can play a critical role in defining the antibacterial activity of nanoclusters. Several reports have indicated that silver nanoclusters are capable of generating excessive amounts of intracellular reactive oxygen species, which is proposed as the major contributing factor defining DNA-AgNCs' antibacterial ability [18,41]. It is also becoming increasingly apparent from recent studies both theoretical [42] and experimental [43] that certain shape, composition, and charge states of DNA-AgNCs can increase the chances of optically "dark" states to exist with highspin multiplicity (doublet and triplet). Therefore, it is not unreasonable to propose that highspin AgNC states may interact with highly abundant triplet oxygen removing the "spin-forbidden" condition and stimulating the transition of triplet to singlet oxygen: ${ }^{3} \mathrm{O}_{2} \rightarrow{ }^{1} \mathrm{O}_{2}$. Since singlet oxygen is far more reactive compared to triplet oxygen, this can explain various antibacterial properties of different DNA-AgNCs and the generation of reactive oxygen species.

In conclusion, nucleic acid-based nanomaterials are often designed based on two rationales: the delivery of functional moieties that can be implemented into the nanoscaffolds and the patterns in recognition of nucleic acids which contribute to the cellular response. DNA-AgNCs offer an approach by which functional fluorescent moieties can contribute to selective growth inhibition of bacterial cultures. The results of this study suggest that the rich optical behavior of the DNA-AgNCs may be tightly linked to the antibacterial properties of this novel class of nanostructures. Excitation-emission pattern, interconversion of emissive states, and their connection with environmental changes are the keys to understanding the mechanism of DNA-AgNC inhibitive action. The results obtained herein warrant further exploration of the antibacterial effects of DNA-AgNCs on both pathogenic and non-pathogenic bacteria species.

\section{Materials and Methods}

Synthesis of DNA-AgNCs. All DNA oligonucleotides were purchased from Integrated DNA Technologies (IDT), Inc. (Coralville, IA, USA) as desalted products and used without further purification. All sequences are listed in the Supplementary Materials. Nuclease-free water was obtained from IDT. Sodium borohydride was purchased from TCI America, Inc. (Portland, OR, USA). In a typical preparation, DNA template (C13, C11, C9, or C7) and $\mathrm{AgNO}_{3}$ aqueous solutions were mixed and incubated for $25 \mathrm{~min}$ at room temperature in ammonium acetate buffer (100 $\mathrm{mM} \mathrm{NH}_{4} \mathrm{OAc}, \mathrm{pH}$ 6.9). $\mathrm{Next}, \mathrm{NaBH}_{4}$ aqueous solution was added and samples were placed on ice and stirred vigorously. The final concentrations (C) of the components were as follows: $\mathrm{C}_{\mathrm{DNA} \text {-template }}=50 \mu \mathrm{M} ; \mathrm{C}_{\mathrm{AgNO}}$ was adjusted to match the number of cytosines in the loop according to ${ }^{*} \mathrm{AgNO}_{3}: \mathrm{C}_{\mathrm{n}} ; \mathrm{C}_{\mathrm{NaBH} 4}: \mathrm{C}_{\mathrm{AgNO} 3}$ was taken at 1:1 ratio and $\mathrm{C}_{\mathrm{NH} 4 \mathrm{Ac}}=4 \mathrm{mM}$. The solution was then incubated in the dark for $24 \mathrm{~h}$ at $4{ }^{\circ} \mathrm{C}$. Synthesized DNA-AgNCs were then purified via a NAP-5 (Cytiva) filtration gel column purchased from Sigma-Aldrich, Inc. (Saint Louis, MO, USA) for fluorescence measurements. Purification was performed according to the protocol supplied by the manufacturer. Final concentrations of DNA-AgNCs obtained after filtration varied between 8-15 $\mu \mathrm{M}$ and were evaluated by taking DNA absorption at $265 \mathrm{~nm}$ wavelength. For antibacterial and 
mammalian cell viability experiments, DNA-AgNCs were purified using $3 \mathrm{kDa}$ Amicon centrifugal filters by washing twice with buffer and diluting to $50 \mu \mathrm{M}$.

Fluorescence measurements. The excitation and emission spectra were acquired on a Duetta-Fluorescence and Absorbance Spectrometer (Horiba, Inc., Chicago, IL, USA). In all the measurements, the concentration of the templating sequence was kept the same at $\sim 6$ $\mu \mathrm{M}$. Fluorescence measurements were carried out in a Sub-Micro Fluorometer Cell, model 16.40F-Q-10 (from StarnaCells, Inc., Atascadero, CA, USA) at room temperature of $\sim 22$ ${ }^{\circ} \mathrm{C}$. The excitation-emission matrix spectra (EEMS) were recorded with $0.5 \mathrm{~nm}$ resolution. Fluorescence spectra were recorded with the emission wavelength range from $300 \mathrm{~nm}$ to $1000 \mathrm{~nm}$, the initial excitation wavelength was set to $280 \mathrm{~nm}$, and the final excitation wavelength was set to $800 \mathrm{~nm}$ with an increment of $0.5 \mathrm{~nm}$. Matrix data were then used for 2D contour plot using MagicPlot Pro software (v2.9, Magicplot Systems, LLC, Saint Petersburg, Russia).

Bacterial growth assays. TOP10F' E. coli were purchased from ThermoFisher Scientific (Walham, MA, USA) and grown in Luria broth (LB) purchased from Sigma. Where shown, the $\mathrm{pH}$ of LB was adjusted to $\mathrm{pH} 5.5$ with $100 \mathrm{mM}$ 2-morpholin-4-yl ethanesulfonic acid (MES). E. coli were grown in LB from single colonies while shaking at $200 \mathrm{rpm}$ at $37^{\circ} \mathrm{C}$ in a GeneMate Incubated Shaker (VWR International, LLC, Radnor, PA, USA). For treatment with AgNCs, bacteria were diluted in LB to an optical density at $600 \mathrm{~nm}\left(\mathrm{OD}_{600}\right)$ of 0.018 0.020. Next, $50 \mu \mathrm{L}$ of diluted bacteria were added to each well of a 96-well flat-bottom, black-walled plate. Purified DNA-AgNCs were added with LB to reach a final volume of $100 \mu \mathrm{L}$ in each well with $4 \mu \mathrm{M}$ final concentration of DNA-AgNCs. Carbenicillin was used as a positive control at a final concentration of $50 \mu \mathrm{g} / \mathrm{mL}(132 \mu \mathrm{M})$. The lids of the plates were hydrophobically treated by filling them with $10 \mathrm{~mL}$ of $20 \%$ ethanol, $0.05 \%$ Triton $\mathrm{X}-100$ for $30 \mathrm{~s}$ [44]. The excess liquid was drained, and the lid was leaned against the back of a fume hood to dry for $30 \mathrm{~min}$ [44]. The lids were parafilmed to the microwell plates to prevent excess evaporation. Microplate optical density measurements were recorded using a Tecan Spark (Tecan Group Ltd., Männedorf, Zürich, Switzerland) microwell plate reader. The plates were shaken for $30 \mathrm{~s}$ between each measurement and were incubated at $37{ }^{\circ} \mathrm{C}$ with $\mathrm{OD}_{600}$ measurements taken every 15 min over $20 \mathrm{~h}$. A minimum of six technical repeats and three biological repeats of each experiment were performed. The time required for each growth curve to reach half its maximum optical density, $t_{1 / 2}$, was calculated with GraphPad Prism 9 (San Diego, CA, USA) using a non-linear fit of the data. The difference between the untreated control $t_{1 / 2}$ and the treatment $t_{1 / 2}$ is reported as $\Delta \mathrm{t}_{1 / 2}$. Additional experiments in Lactobacillus cultures were conducted to understand the effects of DNA-AgNCs on normal microflora (Supplementary Materials).

Mammalian cell viability assays. For all experiments, cells were maintained and cultured at $37^{\circ} \mathrm{C}, 5 \% \mathrm{CO}_{2}$. THP1-Dual ${ }^{\mathrm{TM}}$ cells were purchased from InvivoGen (San Diego, CA, USA) and were maintained in RPMI 1640, $2 \mathrm{mM}$ L-glutamine, $25 \mathrm{mM}$ HEPES, 10\% heatinactivated fetal bovine serum (FBS), and PenStrep (100 U/mL,100 $\mu \mathrm{g} / \mathrm{mL})$. 293FT cells were cultured in DMEM, $2 \mathrm{mM}$ L-glutamine, 10\% FBS, and PenStrep $(100 \mathrm{U} / \mathrm{mL}, 100$ $\mu \mathrm{g} / \mathrm{mL}$ ). Jurkat cells were cultured in RPMI 1640, $2 \mathrm{mM}$ L-glutamine, $25 \mathrm{mM}$ HEPES, 10\% FBS, and PenStrep (100 U/mL, $100 \mu \mathrm{g} / \mathrm{mL}$ ). For cell viability studies, cells were plated in a 96-well flat-bottom plate at a density of 40,000 cells per well along with DNA-AgNC solution at final concentrations of 4 or $8 \mu \mathrm{M}$ and final well volumes of $100 \mu \mathrm{L}$. After incubation with AgNC treatments for 20 h, $20 \mu \mathrm{L}$ of CellTiter $96^{\circledR}$ AQueous One Solution Cell Proliferation Assay (MTS) were added to each well. Plates were incubated for an additional $75 \mathrm{~min}$ at $37^{\circ} \mathrm{C}, 5 \% \mathrm{CO}_{2}$. The plates were then read on a Tecan Spark microplate reader for absorbance at $490 \mathrm{~nm}$. Sixteen reads per well were averaged for each value.

Scanning electron microscopy (SEM) and energy-dispersive X-ray spectroscopy (EDS) elemental analysis. Solutions of $50 \mu \mathrm{M} \mathrm{C7,} \mathrm{C9,} \mathrm{C11,} \mathrm{and} \mathrm{C13} \mathrm{in} \mathrm{buffer} \mathrm{were} \mathrm{pipetted} \mathrm{onto} \mathrm{a}$ polished silicon wafer as $10 \mu \mathrm{L}$ droplets. Droplets were allowed to dry in a covered Petri dish overnight at room temperature. The solid residue was analyzed with SEM/EDS to determine the atomic ratio between P and Ag. Dried solutions on the Si substrate were 
analyzed with a JEOL JSM-6480 SEM. Micrographs were taken in secondary electron mode with an accelerating voltage of $5 \mathrm{kV}$. EDS spectra were collected using an Oxford Instruments INCA EDS behind a beryllium window. Atomic percentages were calculated by the INCA instrument software based on the intensities of phosphorus $\mathrm{K} \alpha(2.013 \mathrm{keV})$ and silver $\mathrm{L} \alpha(2.984 \mathrm{keV})$ characteristic X-rays.

Statistical analysis. All data is presented as the mean \pm standard deviation or standard error of the mean (specified for each case) for a minimum of $N=3$ independent biological replicates. For statistical analysis, a one-way ANOVA was performed, followed by a $t$-test using GraphPad Prism 9.0.0 Software for Windows. P-values of $p<0.05$ were considered statistically significant.

Supplementary Materials: Figure S1. Comparison of C12 template as a single-stranded nucleotide or as a loop in a hairpin structure. (A) AFM image of AgNCs formed on a template containing single-stranded C12 sequence, (B) AFM image of AgNCs formed on a template containing C12 loop, (C) EEM of AgNCs templated on a template containing single-stranded C12 sequence, (D) EEM of AgNCs templated on a template containing C12 loop. Figure S2. Liquid culture growth curves are shown of E. coli which have been treated with varying concentrations of AgNC. Each is shown with the standard deviation as a dotted line on either side of the solid line in the same color. There is a strong dose-dependence for each AgNC with $8 \mu \mathrm{M}$ C11 eliminating growth for almost the full 20 hours. Figure S3. To see the effects of free silver that may not have bound to DNA, $650 \mu \mathrm{M} \mathrm{AgNO3}$ solution was reduced with an equimolar amount of $\mathrm{NaBH} 4$, just as in the synthesis of the $\mathrm{C} 13 \mathrm{AgNC}$. E. coli was then treated with the same amount of this solution as would be present in $4 \mu \mathrm{M} \mathrm{C13} \mathrm{AgNC}$ treatments. While there was a slight reduction in growth rate and the maximum OD600, these were minimal compared to the effects of the $\mathrm{C} 13 \mathrm{AgNC}$ at $4 \mu \mathrm{M}$. Figure S4. Additional mammalian cell viability assays were conducted with $8 \mu \mathrm{M}$ AgNC concentrations following the methods described in the main text. Following 20 hours of incubation at $37^{\circ} \mathrm{C}$ and $5 \% \mathrm{CO} 2$, MTS was added and incubated for an additional 75 minutes at the same conditions. The absorbance was recorded at $490 \mathrm{~nm}$ and the relative cell viability was calculated. No statistically significant reduction in cell viability was found at the elevated AgNC conditions. Figure S5. Secondary electron micrographs of all of the dried AgNC samples which were used for the stoichiometry calculations are shown. Figure S6. (A) Plates of Lactobacilli treated with C7 or C9 AgNCs and the resulting colonies formed. (B) Colony forming units (CFU) $/ \mathrm{mL}$ after treatment with $\mathrm{C} 7$ or $\mathrm{C} 9$ were compared to the control sample Significance of $\mathrm{p}<0.05$ is denoted with an asterisk. Figure S7. Titration of AgNCs with hydrogen peroxide. (I) C7 DNA-AgNCs, (II) C9 DNA-AgNCs, (III) C11 DNA-AgNCs, (IV) C13 DNA-AgNCs. Progressive addition of hydrogen peroxide shows changes in oxidative state of DNA-AgNCs. (a-f) are different ratios of $\mathrm{CAgNC} / \mathrm{CH} 2 \mathrm{O} 2$ = 1/0 (a), 1/1.9 (b), 1/3.8 (c), 1/5.7 (d), 1/7.6 (e), 1/9.5 (f), 1/11.4 (g). Figure S8. Evaluation of optical properties. UV-Vis spectra of (A) C7, (B) C9, (C) C11, (D) C13 samples immediately after purification. Emission spectra with $254 \mathrm{~nm}$ excitation mimicking color observation shown in Figure 1, (E) C7, (F) C9, (G) C11, (H) C13. Excitation spectra for $525 \mathrm{~nm}$ emission peak, (I) C7, (J) C9, (K) C11, (L) C13. Excitation spectra for $635 \mathrm{~nm}$ emission peak, (M) C7, (N) C9, (O) $\mathrm{C} 11,(\mathrm{P}) \mathrm{C} 13$. Table S1. The calculated number of silver atoms from the atomic percentages obtained from the EDS reports are shown with the average and standard error of the mean for each AgNC. References [7,45] are cited in the Supplementary Materials.

Author Contributions: Conceptualization-K.A.A. and A.V.K.; methodology, validation, and formal analysis-L.R., L.Y., M.C., D.B., L.D., S.K., N.M. and O.S. All authors have read and agreed to the published version of the manuscript.

Funding: Research reported in this publication was supported by the National Institute of General Medical Sciences of the National Institutes of Health under Award Number R35GM139587 (to K.A.A.). The content is solely the responsibility of the authors and does not necessarily represent the official views of the National Institutes of Health.

Institutional Review Board Statement: Not applicable.

Informed Consent Statement: Not applicable.

Data Availability Statement: All data are available and can be shared upon request. 
Acknowledgments: The authors would like to thank Brittany Johnson (UNCC) for advice with bacterial studies, the Troutman Lab (UNCC) for use of the Molecular Devices SpectraMax M5 microplate reader for initial data collection, and Ryan Riskowski (UNO) for use of the Duetta Spectrometer. AFM scans were obtained with the use of MultiMode Nanoscope IV system at the Nanoimaging Core Facility, UNMC, and we also thank Alexander Lushnikov (NCF-UNMC) for his assistance in sample preparation for AFM imaging.

Conflicts of Interest: The authors declare no conflict of interest.

Sample Availability: Samples of the DNA-AgNCs are available from the authors.

\section{References}

1. Ritchie, C.M.; Johnsen, K.R.; Kiser, J.R.; Antoku, Y.; Dickson, R.M.; Petty, J.T. Ag Nanocluster Formation Using a Cytosine Oligonucleotide Template. J. Phys. Chem. C 2007, 111, 175-181. [CrossRef] [PubMed]

2. Petty, J.T.; Zheng, J.; Hud, N.V.; Dickson, R.M. DNA-Templated Ag Nanocluster Formation. J. Am. Chem. Soc. 2004, 126, 5207-5212. [CrossRef]

3. Chandler, M.; Shevchenko, O.; Vivero-Escoto, J.L.; Striplin, C.D.; Afonin, K.A. DNA-Templated Synthesis of Fluorescent Silver Nanoclusters. J. Chem. Educ. 2020, 97, 1992-1996. [CrossRef]

4. New, S.Y.; Lee, S.T.; Su, X.D. DNA-templated silver nanoclusters: Structural correlation and fluorescence modulation. Nanoscale 2016, 8, 17729-17746. [CrossRef] [PubMed]

5. Cerretani, C.; Kanazawa, H.; Vosch, T.; Kondo, J. Crystal structure of a NIR-Emitting DNA-Stabilized Ag 16 Nanocluster. Angew. Chem. 2019, 131, 17313-17317. [CrossRef]

6. Huard, D.J.E.; Demissie, A.; Kim, D.; Lewis, D.; Dickson, R.M.; Petty, J.T.; Lieberman, R.L. Atomic Structure of a Fluorescent Ag8 Cluster Templated by a Multistranded DNA Scaffold. J. Am. Chem. Soc. 2019, 141, 11465-11470. [CrossRef] [PubMed]

7. O'Neill, P.R.; Gwinn, E.G.; Fygenson, D.K. UV Excitation of DNA Stabilized Ag Cluster Fluorescence via the DNA Bases. J. Phys. Chem. C 2011, 115, 24061-24066. [CrossRef]

8. Lee, T.-H.; Gonzalez, J.I.; Zheng, J.; Dickson, R.M. Single-Molecule Optoelectronics. Acc. Chem. Res. 2005, 38, 534-541. [CrossRef]

9. Gwinn, E.G.; O’Neill, P.; Guerrero, A.J.; Bouwmeester, D.; Fygenson, D.K. Sequence-Dependent Fluorescence of DNA-Hosted Silver Nanoclusters. Adv. Mater. 2008, 20, 279-283. [CrossRef]

10. Gwinn, E.; Schultz, D.; Copp, S.; Swasey, S. DNA-Protected Silver Clusters for Nanophotonics. Nanomaterials 2015, 5, 180-207. [CrossRef]

11. Yin, N.; Yuan, S.; Zhang, M.; Wang, J.; Li, Y.; Peng, Y.; Bai, J.; Ning, B.; Liang, J.; Gao, Z. An aptamer-based fluorometric zearalenone assay using a lighting-up silver nanocluster probe and catalyzed by a hairpin assembly. Microchim. Acta 2019, 186, 1-8. [CrossRef]

12. Afonin, K.A.; Schultz, D.; Jaeger, L.; Gwinn, E.; Shapiro, B.A. Silver Nanoclusters for RNA Nanotechnology: Steps towards Visualization and Tracking of RNA Nanoparticle Assemblies; Springer: New York, NY, USA, 2015; pp. 59-66.

13. Afonin, K.A.; Dobrovolskaia, M.A.; Church, G.; Bathe, M. Opportunities, Barriers, and a Strategy for Overcoming Translational Challenges to Therapeutic Nucleic Acid Nanotechnology. ACS Nano 2020, 14, 9221-9227. [CrossRef] [PubMed]

14. Feng, Q.L.; Wu, J.; Chen, G.Q.; Cui, F.Z.; Kim, T.N.; Kim, J.O. A mechanistic study of the antibacterial effect of silver ions on Escherichia coli and Staphylococcus aureus. J. Biomed. Mater. Res. 2000, 52, 662-668. [CrossRef]

15. Sondi, I.; Salopek-Sondi, B. Silver nanoparticles as antimicrobial agent: A case study on E-coli as a model for Gram-negative bacteria. J. Colloid Interface Sci. 2004, 275, 177-182. [CrossRef] [PubMed]

16. Morones, J.R.; Elechiguerra, J.L.; Camacho, A.; Holt, K.; Kouri, J.B.; Ramirez, J.T.; Yacaman, M.J. The bactericidal effect of silver nanoparticles. Nanotechnology 2005, 16, 2346-2353. [CrossRef] [PubMed]

17. Banerjee, I.; Pangule, R.C.; Kane, R.S. Antifouling Coatings: Recent Developments in the Design of Surfaces that Prevent Fouling by Proteins, Bacteria, and Marine Organisms. Adv. Mater. 2011, 23, 690-718. [CrossRef]

18. Javani, S.; Lorca, R.; Latorre, A.; Flors, C.; Cortajarena, A.L.; Somoza, Á. Antibacterial Activity of DNA-Stabilized Silver Nanoclusters Tuned by Oligonucleotide Sequence. ACS Appl. Mater. Interfaces 2016, 8, 10147-10154. [CrossRef]

19. Yang, L.; Yao, C.; Li, F.; Dong, Y.; Zhang, Z.; Yang, D. Synthesis of Branched DNA Scaffolded Super-Nanoclusters with Enhanced Antibacterial Performance. Small 2018, 14, 1800185. [CrossRef]

20. Eun, H.; Kwon, W.Y.; Kalimuthu, K.; Kim, Y.; Lee, M.; Ahn, J.-O.; Lee, H.; Lee, S.H.; Kim, H.J.; Park, H.G.; et al. Melaminepromoted formation of bright and stable DNA-silver nanoclusters and their antimicrobial properties. J. Mater. Chem. B 2019, 7, 2512-2517. [CrossRef]

21. Sengupta, B.; Sinha, S.S.; Garner, B.L.; Arany, I.; Corley, C.; Cobb, K.; Brown, E.; Ray, P.C. Influence of Aptamer-Enclosed Silver Nanocluster on the Prevention of Biofilm by Bacillus thuringiensis. Nanosci. Nanotechnol. Lett. 2016, 8, 1054-1060. [CrossRef]

22. Panigaj, M.; Johnson, M.B.; Ke, W.; McMillan, J.; Goncharova, E.A.; Chandler, M.; Afonin, K.A. Aptamers as Modular Components of Therapeutic Nucleic Acid Nanotechnology. ACS Nano 2019, 13, 12301-12321. [CrossRef]

23. Yourston, L.E.; Lushnikov, A.Y.; Shevchenko, O.A.; Afonin, K.A.; Krasnoslobodtsev, A.V. First Step Towards Larger DNABased Assemblies of Fluorescent Silver Nanoclusters: Template Design and Detailed Characterization of Optical Properties. Nanomaterials 2019, 9, 613. [CrossRef] 
24. Guo, Y.; Shen, F.; Cheng, Y.; Yu, H.; Xie, Y.; Yao, W.; Pei, R.; Qian, H.; Li, H.-W. DNA-Hairpin-Templated Silver Nanoclusters: A Study on Stem Sequence. J. Phys. Chem. B 2020, 124, 1592-1601. [CrossRef]

25. Ramsay, H.; Simon, D.; Steele, E.; Hebert, A.; Oleschuk, R.D.; Stamplecoskie, K.G. The power of fluorescence excitation-emission matrix (EEM) spectroscopy in the identification and characterization of complex mixtures of fluorescent silver clusters. RSC Adv. 2018, 8, 42080-42086. [CrossRef]

26. Yourston, L.; Rolband, L.; Lushnikov, A.; West, C.; Afonin, K.; Krasnoslobodtsev, A. Tuning properties of silver nanoclusters with RNA nanoring assemblies. Nanoscale 2020, 12, 16189-16200. [CrossRef] [PubMed]

27. Yourston, L.E.; Krasnoslobodtsev, A.V. Micro RNA Sensing with Green Emitting Silver Nanoclusters. Molecules 2020, 25, 3026. [CrossRef]

28. Petty, J.T.; Sergev, O.O.; Kantor, A.G.; Rankine, I.J.; Ganguly, M.; David, F.D.; Wheeler, S.K.; Wheeler, J.F. Ten-Atom Silver Cluster Signaling and Tempering DNA Hybridization. Anal. Chem. 2015, 87, 5302-5309. [CrossRef]

29. Chaloupka, K.; Malam, Y.; Seifalian, A.M. Nanosilver as a new generation of nanoproduct in biomedical applications. Trends Biotechnol. 2010, 28, 580-588. [CrossRef]

30. Deshmukh, S.P.; Patil, S.M.; Mullani, S.B.; Delekar, S.D. Silver nanoparticles as an effective disinfectant: A review. Mater. Sci. Eng. C 2019, 97, 954-965. [CrossRef]

31. Cerretani, C.; Vosch, T. Switchable Dual-Emissive DNA-Stabilized Silver Nanoclusters. ACS Omega 2019, 4, 7895-7902. [CrossRef]

32. Shah, P.; Rørvig-Lund, A.; Chaabane, S.B.; Thulstrup, P.W.; Kjaergaard, H.G.; Fron, E.; Hofkens, J.; Yang, S.W.; Vosch, T. Design Aspects of Bright Red Emissive Silver Nanoclusters/DNA Probes for MicroRNA Detection. ACS Nano 2012, 6, 8803-8814. [CrossRef]

33. Enkin, N.; Wang, F.; Sharon, E.; Albada, H.B.; Willner, I. Multiplexed Analysis of Genes Using Nucleic Acid-Stabilized SilverNanocluster Quantum Dots. ACS Nano 2014, 8, 11666-11673. [CrossRef] [PubMed]

34. Tian, X.; Jiang, X.; Welch, C.; Croley, T.R.; Wong, T.-Y.; Chen, C.; Fan, S.; Chong, Y.; Li, R.; Ge, C.; et al. Bactericidal Effects of Silver Nanoparticles on Lactobacilli and the Underlying Mechanism. ACS Appl. Mater. Interfaces 2018, 10, 8443-8450. [CrossRef] [PubMed]

35. Verdolino, V.; Cammi, R.; Munk, B.H.; Schlegel, H.B. Calculation of pKa Values of Nucleobases and the Guanine Oxidation Products Guanidinohydantoin and Spiroiminodihydantoin using Density Functional Theory and a Polarizable Continuum Model. J. Phys. Chem. B 2008, 112, 16860-16873. [CrossRef]

36. Gambucci, M.; Cerretani, C.; Latterini, L.; Vosch, T. The effect of $\mathrm{pH}$ and ionic strength on the fluorescence properties of a red emissive DNA-stabilized silver nanocluster. Methods Appl. Fluoresc. 2019, 8, 014005. [CrossRef]

37. Copp, S.M.; Schultz, D.; Swasey, S.; Pavlovich, J.; Debord, M.; Chiu, A.; Olsson, K.; Gwinn, E. Magic Numbers in DNA-Stabilized Fluorescent Silver Clusters Lead to Magic Colors. J. Phys. Chem. Lett. 2014, 5, 959-963. [CrossRef]

38. Weerawardene, K.L.D.M.; Häkkinen, H.; Aikens, C.M. Connections Between Theory and Experiment for Gold and Silver Nanoclusters. Annu. Rev. Phys. Chem. 2018, 69, 205-229. [CrossRef]

39. Le Ouay, B.; Stellacci, F. Antibacterial activity of silver nanoparticles: A surface science insight. Nano Today 2015, 10, 339-354. [CrossRef]

40. Lakowicz, J.R. Principles of Fluorescence Spectroscopy, 3rd ed.; Springer: New York, NY, USA, 2006.

41. Yuan, X.; Setyawati, M.I.; Tan, A.S.; Ong, C.N.; Leong, D.T.; Xie, J. Highly luminescent silver nanoclusters with tunable emissions: Cyclic reduction-decomposition synthesis and antimicrobial properties. NPG Asia Mater. 2013, 5, e39. [CrossRef]

42. Jabed, M.A.; Dandu, N.; Tretiak, S.; Kilina, S. Passivating Nucleobases Bring Charge Transfer Character to Optically Active Transitions in Small Silver Nanoclusters. J. Phys. Chem. A 2020, 124, 8931-8942. [CrossRef]

43. Krause, S.; Cerretani, C.; Vosch, T. Disentangling optically activated delayed fluorescence and upconversion fluorescence in DNA stabilized silver nanoclusters. Chem. Sci. 2019, 10, 5326-5331. [CrossRef]

44. Brewster, J.D. A simple micro-growth assay for enumerating bacteria. J. Microbiol. Methods 2003, 53, 77-86. [CrossRef]

45. O'Neill, P.R.; Velazquez, L.R.; Dunn, D.G.; Gwinn, E.G.; Fygenson, D.K. Hairpins with Poly-C Loops Stabilize Four Types of Fluorescent Agn:DNA. J. Phys. Chem. C 2009, 113, 4229-4233. [CrossRef] 